\title{
EXPLANATORY STYLE AND GAMBLING: HOW PESSIMISTS RESPOND TO LOSING WAGERS
}

\author{
Gordon D. Atlas' and Christopher Peterson ${ }^{2}$ \\ 'Department of Psychology, Alfred University, Alfred, NY 14802 and \\ ${ }^{2}$ University of Michigan, Ann Arbor, MI 48109, U.S.A.
}

(Received 29 June 1990)

\begin{abstract}
Summary-Fifty-three patrons of a hariess racing track completed two measures of explanatory style prior to an afternoon's races. One measure assessed general explanatory style, using bad events taken from the Attributional Style Questionnaire, and the other measure assessed betting-specific explanatory style, using bad events specific to harness race betting. Subjects then kept a diary during the first eight races. After each race, they reported how much they had bet, whether they had won or lost, the major cause of the outcome, their confidence about winning future bets, and whether they were ruminating about past or future races. Explanatory style assessed in both ways had similar correlates. Explanatory style predicted the specific attributions made by subjects for losses. Pessimistic explanatory style (internal + stable + global attributions) predicted rumination following a lost bet, but it was unrelated to expressed confidence. Rumination after a loss was in turn associated with larger wagers on subscquent races and a tendency toward less successful wagers. These results clarify one way in which pessimistic explanatory style results in helplessness, and suggest a path by which problematic gambling may develop.
\end{abstract}

Explanatory style is a cognitive personality variable reflecting how people habitually explain the causes of bad events (Peterson \& Seligman, 1984). It is generally measured with the Attributional Style Questionnaire (ASQ; Peterson, Semmel, von Baeyer, Abramson, Metalsky \& Seligman, 1982), which presents respondents with hypothetical bad events and asks them to provide the cause of the event occurring to them. Some people explain bad events by pointing to factors within themselves that are chronic and pervasive (e.g. "I'm a loser" whereas others explain negative outcomes in terms of circumscribed causes outside themselves (e.g. "It was an accident"). We refer to the former people as pessimistic or helpless, and to the latter as optimistic or efficacious (Peterson, Seligman \& Vaillant, 1988). According to theory and research, pessimistic individuals are more likely than their optimistic counterparts to respond with passivity and low morale to actual bad events.

The initial work on explanatory style emerged from the reformulated learned helplessness model of depression (Abramson, Seligman \& Teasdale, 1978). Much of the research on explanatory style, in fact, has focused on its relationship to depression (Sweeney, Anderson \& Bailey, 1986). On the basis of a series of studies in various contexts with different populations, pessimistic explanatory style has been established as a risk factor for depression (Peterson \& Seligman, 1984).

More recently, though, work on explanatory style has been extended in two directions. Researchers have begun to examine the effects of pessimistic explanatory style in various domains. For example, college students' explanatory style has been shown to affect their academic performance, even when measures of scholastic aptitude are held constant (Peterson \& Barrett, 1987). Pessimistic individuals working in sales stay for shorter amounts of time at their jobs, and are less effective than their 'optimistic' counterparts (Seligman \& Schulman, 1986). Another approach has been to examine the physical effects of pessimistic explanatory style. Here, pessimistic explanatory style has been found to be a risk factor for poor physical health (Peterson, 1988; Peterson \& Seligman, 1987). Some evidence suggests, in fact, that one's explanatory style may even have an impact upon longevity (Peterson et al., 1988).

The reformulated learned helplessness model has assumed that these consequences of pessimistic explanatory style have their source in how an individual responds to uncontrollable bad events. Pessimists presumably respond to these situations with maladaptive passivity (Seligman, 1975). By viewing the bad event as both global and also stable, they enlarge the difficulty and are unable to rebound, whereas their optimistic counterparts respond with renewed effort and perseverance. 
Other theorists have proposed that the helpless person tends to ruminate following bad events, thus encouraging task-irrelevant thoughts which affect subsequent performance (Kuhl, 1981).

How pessimists actually respond to bad events, however, has thus far been largely overlooked in empirical studies. Much research has attended to the consequences of making certain kinds of characteristic attributions following hypothetical bad events without attending to the actual attributions made regarding actual bad events. Indeed, this has been one criticism which has been made regarding the reformulated helplessness model (Coyne \& Gotlib, 1983). Some evidence for the link between hypothetical and actual attributions has been offered (Peterson, Bettes \& Seligman, 1985; Peterson \& Villanova, 1988), but the connection is crucial in establishing the process by which pessimism leads to negative behavioral and physical consequence and thus deserves further attention.

Researchers have also only begun to trace the affective and behavioral consequences of experiencing bad events for the pessimist. Again, this is partly a function of the tendency to examine only the distal relationship between the independent variable as measured by responses to hypothetical bad events, and its outcomes (e.g. depression, academic performance, health). How does the pessimist respond to a bad event? Does helplessness lead to behavioral and affective paralysis? Some evidence suggests that pessimistic explanatory style influences problem-solving (Alloy, Peterson, Abramson \& Seligman, 1984), but even this work did not examine responses to actual bad events. By ignoring actual bad events, researchers have in effect collapsed across individuals who have and have not experienced a setback, thus providing a weak test of the helplessness model (Peterson \& Seligman, 1984).

One further criticism which has been directed against the current body of literature on explanatory style has been its reliance upon college populations for its $S$ s. Although some of the work on depression has been able to demonstrate a similar relationship between explanatory style and depression in non-college samples (Sweeney et al., 1986), there is a continuing need to extend this research to 'natural populations'.

These criticisms serve as the point of departure for the study reported in the present paper. We attempt to improve upon typical investigations of explanatory style by addressing some of these traditional areas of weakness. We studied the explanatory style of individuals patronizing a harness racing track. Our $S$ s completed a measure of explanatory style before the races began, and then kept a race-by-race journal of their subsequent thoughts and actions.

The benefits of this paradigm are several. Obviously, we are studying a population quite different from the ones from which previous samples have been drawn. Because one day of harness racing consists of a number of races, on which most patrons bet and on which most patrons lose, we have the opportunity to study the responses of $S s$ to a series of bad events. Following each race, moreover, the patrons face a task made important by the money involved: how and what to wager on the next race. We are thus able to examine at least a part of the subsequent decision-making proceess that takes place following a bad event.

In examining the responses of $S \mathrm{~s}$ to bad events, we chose to focus on the possible role of rumination (Kuhl, 1981), both as a reaction to the bad event and in terms of its impact on subsequent decision-making. Pessimists should not only overgeneralize and exaggerate the importance of the bad event, as Beck's cognitive theory suggests (1967), but express less confidence about the success of subsequent wagers, and make poor decisions in those wagers.

One additional question of interest in the present study was whether explanatory style measures specifically tailored to the outcomes of interest yield stronger correlations than do general measures of explanatory style. No one has specifically investigated this idea, although it has been alluded to by Peterson and Barrett (1987), who recommended domain-specific measures in order to bolster predictability. In the present research, then, we measured both general explanatory style at.t horse-racing-betting-specific explanatory style.

In sum, here are the major hypotheses to be evaluated in the present investigation.

Hypothesis 1. Explanatory style assessed from attributions about hypothetical bad events predicts one's attributions about actual bad events.

Hypothesis 2. Pessimistic explanatory style, following a bad event (losing a bet) leads to helplessness, as shown by lack of confidence, rumination, and poor decisions regarding subsequent bets. 
Hypothesis 3. Hypotheses 1 and 2 are supported more consistently when explanatory style is measured from attributions about betting events than when it is measured from attributions about general bad events.

\section{METHOD}

\section{Subjects}

Fifty-three race track bettors ( 31 males, 22 females) participated in this study. $S$ s were solicited by a poster upon entering Jackson (Michigan) Harness Raceway on two separate occasions during the summer of 1987 . They were offered $\$ 10$ to complete the study. The average $S$ was $43 \mathrm{yr}$ of age, and reported attending harness racing 39 times per year, bringing $\$ 80$ on each occasion. The average $S$ claimed that he or she usually broke even or came out ahead after a day of gambling. (Present data suggests this to be an exaggeration.) $S$ s did not come to the racetrack in order to participate in the study. Rather, they attended to bet and only decided to serve as a $S$ once they noticed our poster.

\section{Procedure}

$S$ was given a booklet containing a brief demographic questionnaire, a short version of the Attributional Style Questionnaire, a measure developed for the present research dubbed the Betting Attributional Style Questionnaire (BASQ), and a Response to Race Outcome Diary containing one page for each of the first eight races of the afternoon.

The demographic measure, the ASQ, and the BASQ were completed prior to the beginning of the first race. The appropriate questions of the Response to Race Outcome Diary were completed following each of the first eight races. After the eighth race, $S$ s returned the diary to the researchers and were paid $\$ 10$.

\section{Measures}

$A S Q$. The version of the Attributional Style Questionnaire used in this study was identical to the usual measure (Peterson et al., 1982), except that only four hypothetical bad events (and no good events) were included (see Table 1). For each event, $S_{\mathrm{s}}$ were asked to imagine that it had happened to them and to provide in writing the 'one major cause' of this event if it were to happen. $S$ s are then asked to rate this cause on 7-point scales according to its internality $(=7)$ vs externality $(=1)$, stability $(=7)$ vs instability $(=1)$, and globality $(=7)$ vs specificity $(=1)$.

Higher scores-indicating internal, stable, and global attributions-were regarded as pessimistic and lower scores as optimistic. Following convention, scores for a given $S$ were averaged across events and across dimensions. The reliability of the ASQ in the present sample, estimated by Cronbach's (1951) coefficient $\alpha$, was 0.68 . Its mean was 3.91, and its standard deviation was 1.01 .

$B A S Q$. The Betting Attributional Style Questionnaire was strictly parallel to the ASQ except that the four hypothetical bad events used were specific to betting on harness races (again see Table 1). The reliability of this measure in the present sample, estimated by Cronbach's (1951) coefficient $\alpha$, was 0.78 . Its mean was 3.79 , and its standard deviation was 1.15 .

Response to race outcome diary. This diary asked the same questions about each of the first eight races of the afternoon. First, $S$ s specified the amount of their bet and whether they won or lost it.

Second, $S$ s were asked to provide the cause for the race turning out as it did (won or loss). Following the format of the ASQ and the BASQ, $S$ s rated the attributed cause on 7-point scales

Table 1. Hypothetical bad events comprising the ASQ and BASQ

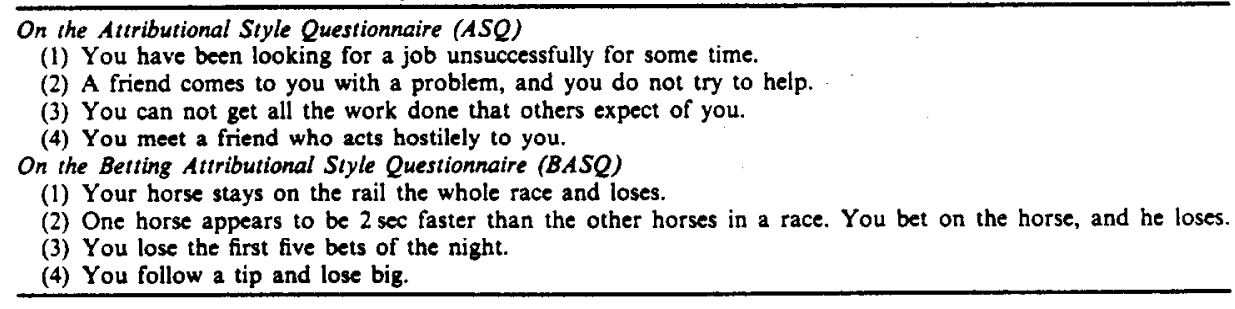


Table 2. Correlations between explanatory style and actual attributions following losing races

\begin{tabular}{|c|c|c|c|c|c|c|c|c|c|}
\hline \multirow[b]{2}{*}{ Explanatory style } & \multicolumn{8}{|c|}{ Races } & \multirow[b]{2}{*}{ Composite } \\
\hline & I & 2 & 3 & 4 & 5 & 6 & 7 & 8 & \\
\hline ASQ & $0.34^{\circ}$ & 0.32 & $0.47^{* *}$ & 0.18 & $0.45^{* *}$ & $0.34 *$ & 0.05 & 0.07 & $0.44^{* *}$ \\
\hline BASQ & $0.44 * *$ & 0.25 & 0.21 & 0.27 & 0.18 & 0.27 & -0.04 & $0.41 *$ & $0.37^{* *}$ \\
\hline$A S Q$ and $B A S Q$ & $0.42^{* *}$ & 0.30 & $0.38^{*}$ & 0.24 & $0.36^{*}$ & $0.35^{*}$ & 0.00 & $0.49 * *$ & $0.45^{* *}$ \\
\hline
\end{tabular}

corresponding to its internality vs externality and to its stability vs instability. Because stability and globality ratings prove highly redundant (Peterson, Villanova \& Raps, 1985), we chose not to ask about the globality of the attributed cause, in order to reduce respondent burden.

Third, $S$ s rated their confidence in winning money on the next race on a 7-point scale $(1=$ not at all and $7=$ a great deal). Fourth, $S$ s used 7-point scales to report the degree they were thinking about past races and the degree they were thinking about future races $(1=$ not at all and $7=a$ great deal). These scores comprised our measure of rumination.

\section{RESULTS}

Here is an overview of the results. Explanatory style assessed from attributions about hypothetical bad events indeed predicted actual attributions for losing wagers. Pessimistic explanatory style predicted rumination following a lost bet, but it did not relate to expressed confidence. Rumination following a loss was in turn correlated with larger wagers on subsequent races and somewhat with decreased success at these wagers. General explanatory style and betting-specific explanatory style showed the same pattern of correlates.

Strategy of analysis. The ASQ and the BASQ were highly correlated $(r=0.70, P<0.0001)$, at about the level of the reliabilities of these measures, suggesting that these were not measuring distinct aspects of explanatory style. Nonetheless, in view of Hypothesis 3, correlations for both measures will be reported throughout, along with correlations involving a composite measure of the two (mean $=3.85, \mathrm{SD}=0.98, \alpha=0.83$ ).

Because the helplessness predictions are most relevant following a bad event, it was important to analyze $S s^{\prime}$ responses only for races in which they had made a losing bet. For any given race, however, some $S$ s did make a winning bet, which reduced the degrees of freedom to an unsatisfactory number. Composite measures were thus calculated for the responses in the diary that followed a loss by averaging these across the appropriate items. For instance, if a $S$ made a losing bet on the first, third, fifth, and seventh races, then scores were formed by averaging across diary entries following these four races only. Every $S$ lost at least two bets, and the range of losses was between 2 and 8 (averaging 5.25).

Testing the hypotheses. Table 2 shows the correlations between explanatory style and the actual attributions made by $S \mathrm{~s}$ for races they lost. Note that these were generally significant, showing that explanatory style as measured from hypothetical events predicts actual explanations for bad events. Hypothesis 1 was, generally, supported.

How did explanatory style relate to the other measures from the diary? Table 3 shows that pessimistic explanatory style was linked as predicted to rumination following a loss, but was unrelated to confidence or success at future betting. Pessimists tended to focus on past races $(r=0.31, P<0.01)$ as well as future races $(r=0.26, P<0.05)$ following a loss. 'Thinking about past races' and 'thinking about future races' were themselves very highly correlated $(r=0.49$, $P<0.001$ ), supporting our decision to combine them to produce our measure of rumination.

Although there was no overall relationship between explanatory style and subsequent betting (although a trend in the predicted direction did emerge), analysis of the results for individual races

Table 3. Correlations between explanatory style and responses to losing wagers

\begin{tabular}{|c|c|c|c|c|c|}
\hline \multirow[b]{2}{*}{ Explanatory style } & \multicolumn{5}{|c|}{ Rumination } \\
\hline & Past & Future & Composite & Confidence & Success of next bet \\
\hline $\begin{array}{l}\text { ASQ } \\
\text { BASQ } \\
A S Q \text { and BASQ }\end{array}$ & $\begin{array}{l}0.31^{*} \\
0.27^{*} \\
0.32^{*}\end{array}$ & $\begin{array}{l}0.26^{*} \\
0.20 \\
0.25^{*}\end{array}$ & $\begin{array}{l}0.33^{* *} \\
0.27^{*} \\
0.33^{* *}\end{array}$ & $\begin{array}{r}-0.07 \\
0.09 \\
0.02\end{array}$ & $\begin{array}{l}-0.17 \\
-0.14 \\
-0.17\end{array}$ \\
\hline
\end{tabular}


Table 4. Correlations between rumination following a loss and subsequent decision-making

\begin{tabular}{lcc}
\hline Rumination & Amount of bet & Success of bet \\
\hline About past & 0.19 & -0.10 \\
About future & $0.29^{*}$ & $-0.23^{*}$ \\
Composite (past and future) & $0.28^{*}$ & -0.21 \\
\hline$*<0.05$. & &
\end{tabular}

did reveal two intriguing findings. Following a losing bet in race three, $S$ s with a pessimistic explanatory style were more likely to bet more on race four than those with an 'optimistic' style $(r=0.45, P<0.004)$. After losing their wager in race five, pessimistic $S$ s were more likely to lose their bet on race six $(r=0.37, P<0.02)$. A trend in which pessimism leads to poor decision-making following a bad event was thus at least suggested in our data.

When rumination following a loss was correlated with betting and winning on subsequent races, an interesting pattern emerged (Table 4). Ruminators tended to bet more money following a loss $(r=0.28, P<0.05)$, and were also somewhat less likely to win these bets $(r=-0.21, P<0.10)$. These results are ambiguous, though, because of our strategy of forming composite scores by collapsing across the eight races. We wish to argue that rumination leads to poor decision-making, but the obtained correlations may show merely that losing large bets on early races leads to rumination after later races.

To examine this alternative account, we analyzed the relationship between rumination and subsequent betting on a race-by-race basis. Although not all of these correlations attained statistical significance (because of the reduced degrees of freedom), in these individual cases the pattern was the same as we found for the composite measures: rumination was correlated with larger wagers but reduced success. And in these cases we know that the direction of the correlation had to lead from rumination to betting.

Hypothesis 3 was not supported. For the most part, the ASQ and BASQ had correlates of similar magnitude. The only exceptions were the results just described for betting and losing, where the BASQ predicted slightly better than the ASQ.

\section{DISCUSSION}

The present results support the reformulated learned helplessness model and extend what we know about people's responses to bad events in four important ways. First, explanatory style assessed from attributions about hypothetical events indeed predicts the actual attributions that people offer for bad events. Note that we measured actual attributions for several actual bad events (cf. Peterson et al., 1985), doubtlessly boosting the reliability of the resulting scores through aggregation (cf. Epstein, 1980).

Second, the ASQ and the BASQ had similar correlates, showing that the particular events used to elicit explanatory style are less critical than had been previously thought (Peterson \& Barrett, 1987). Researchers can thus feel more confident about using the 'generic' ASQ without tailoring it explicitly to the outcomes of interest.

Third, pessimistic explanatory style was associated with increased rumination following a loss, and increased rumination in turn was associated with poor decision-making, as shown by increased wagering yet decreased winning. This pattern of findings supports the argument by Kuhl (1981) that helplessness involves extraneous thoughts.

Pessimists, we speculate, are seemingly distracting themselves by ruminating about past races rather than directing their attention to the task at hand. Why would a focus on future races also be considered rumination? Several reasons lead us to believe that this is the case. Focusing on 'future races' rather than the one which is about to occur can be conceptualized as a distracting cognitive activity. Also, the two measures are, again, highly correlated, thus leading us to believe that they represent a single factor (of rumination). Finally, pessimists viewed the bad events as stable-meaning that they might expect subsequent races to have similar negative outcomes. The focus on future races, then, may have been with the thought that this (bad event) will probably recur, thus representing another form of rumination. 
Fourth, perhaps explanatory style warrants further study by clinical psychologists interested in 'compulsive' gambling. We have no way of knowing if any of our $S$ s had a problem with excessive betting, but certainly these results imply a path by which gambling problems might result. If pessimists tend to ruminate following losses, and rumination tends to lead to larger and more unsuccessful bets following losses, this could create a vicious circle from which escape may be difficult.

Limitations of the study exist and must be acknowledged. The results are correlational and perhaps third variables confound some of the patterns we report. Although our design began as longitudinal, the necessity to boost degrees of freedom for analyses necessitated the collapsing of measures across the eight races, resulting in cross-sectional data. Finally, our study was still not as fine-grained as needed to glimpse closely at the cognitive processes by which helplessness is produced in pessimists but not optimists. For instance, we did not ask our $S$ s to specify the aspects of past and future races about which they were ruminating, leaving us to speculate about the content of those 'ruminations'. We do not understand the significance of the 'no finding' concerning expressed confidence. We also did not ascertain the odds of their wagers. It is our suspicion that 'ruminators' made riskier decisions (betting on longer odds horses) because their rate of success was lower, following losing races.

There is one puzzle concerning the entire pattern of results. 'Helplessness' was arguably present in the form of impaired decision-making, but the pessimistic bettors were just as likely as the optimists to continue to bet. One might expect those with a pessimistic explanatory style to stop betting altogether after a loss, to withdraw-but this did not occur. Perhaps a solution to this puzzle can be derived from research literature on animal helplessness, where it is found that passivity following a bad event occurs only when an effortful response is required (Maier \& Seligman, 1976). Perhaps making one more bet at a race track for a habitual bettor does not require enough effort to produce a behavioral passivity that one might expect in pessimists. Another hint comes from our own data; pessimists did not lose confidence following a loss, so why would they withdraw from betting? This suggests that the behavior might have been so habitual for our $S$ s that a complete withdrawal from the activity would not be expected.

In sum, we investigated explanatory style among patrons of a harness racing track. The way they habitually explained bad events predicted the actual explanations they offered for lost wagers. Pessimistic explanatory style predicted rumination about races, which in turn was related to poor decision-making in regard to subsequent races. These results extend and clarify the reformulation of the learned helplessness model in several ways, and suggest a possible path by which excessive gambling could develop.

Acknowledgements - This research was supported by the Faculty Assistance Fund of the College of Literature, Science, and the Arts at the University of Michigan. We thank Daniel Healy and Marie Ziarno for their help in gathering the data. Sam Reichard of Jackson Harness Raceway made it possible for us to do this study, and we thank him.

\section{REFERENCES}

Abramson, L. Y., Seligman, M. E. P. \& Teasdale, J. D. (1978). Learned helplessness in humans: Critique and reformulation. Journal of Abnormal Psychology, 87, 32-48.

Alloy, L. B., Peterson, C., Abramson, L. Y. \& Seligman, M. E. P. (1984). Attributional style and the generality of learned helplessness. Journal of Personality and Social Psychology, 46, 681-687.

Beck, A. T. (1967). Depression: Clinical, experimental and theoretical aspects. New York: Hoeber.

Coyne, J. C. \& Gotlib, I. H. (1983). The role of cognition in depression: A critical appraisal. Psychological Bulletin, 94, $472-505$.

Cronbach, L. J. (1951). Coefficient alpha and the internal structure of tests. Psychometrika, 16, 297-334.

Epstein, S. (1980). The stability of behavior: II. Implications for psychological research. American Psychologist, 35 , 790-806.

Kuhl, J. (1981). Motivational and functional helplessness: The moderating effect of state versus action orientation. Journal of Personality and Social Psychology, 40, 155-170.

Maier, S. F. \& Seligman, M. E. P. (1976). Learned helplessness: Theory and evidence. Journal of Experimental Psychology: General, 105, 3-46.

Peterson, C. (1988). Explanatory style as a risk factor for illness. Cognitice Therapy and Research, 12, 117-130.

Peterson, C. \& Barrett, L. C. (1987). Explanatory style and academic performance among university freshmen. Journal of Personality and Social Psychology, 53, 603-607.

Peterson, C. \& Seligman, M. E. P. (1984). Causal explanations as a risk factor for depression: Theory and evidence. Psychological Review, 91, 347-374.

Peterson, C. \& Seligman, M. E. P. (1987). Explanatory style and illness. Journal of Personality, 55, 237-265. 
Peterson, C. \& Villanova, P. (1988). An expanded attributional style questionnaire. Journal of Abnormal Psychology, 97. 87-89.

Peterson, C., Bettes, B. A. \& Seligman, M. E. P. (1985). Depressive symptoms and unprompted causal attributions: Content analysis. Behaviour Research and Therapy, 23, 379-382.

Peterson, C., Seligman, M. E. P. \& Vaillant, G. E. (1988). Pessimistic explanatory style is a risk factor for physical illness: A thirty-five year longitudinal study. Journal of Personality and Social Psychology, 55, 23-27.

Peterson, C., Villanova, P. \& Raps, C. S. (1985). Depression and attributions: Factors responsible for inconsistent results in the published literature. Journal of Abnormal Psychology, 94, 165-169.

Peterson, C., Semmel, A., von Bayer, C., Abramson, L. Y., Metalsky, G. I. \& Seligman, M. E. P. (1982). The attributional style questionnaire. Cognitive Therapy and Research, 6, 287-300.

Seligman, M. E. P. (1975). Helplessness: On depression, development and death. San Francisco: Freeman.

Seligman, M. E. P. \& Schulman, P. (1986). Explanatory style as a predictor of productivity and quitting among life insurance agents. Journal of Personality and Social Psychology, 50, 832-838.

Sweeney, P. D., Anderson, K. \& Bailey, S. (1986). Attributional style in depression: A meta-analytic review. Journal of Personality and Social Psychology, So, 974-991. 